\title{
A Sentença Normativa e o Direito do Trabalho.
}

\author{
Amauri Mascaro Nascimento \\ Professor Titular de Direito do Trabalho da Faculdade \\ de Direito da Universidade de São Paulo.
}

\section{As Formas do Direito do Trabalho}

A teoria das fontes do Direito do Trabalho incluiu a sentença normativa dentre as figuras de que se compõe o seu amplo quadro, caracterizado por aspectos particulares que se relacionam com as peculiaridades de um setor especial da ordem jurídica.

Basta ver a dimensão que a sentença normativa ocupa na teoria do regulamento coletivo trabalhista.

As normas jurídicas trabalhistas são pluricêntricas, isto é, provêm de diversas fontes de produção, não só do Estado como também de outros grupos sociais, como as organizações sindicais e a empresa.

Essas normas são individuais, quando ajustadas para regular uma determinada e específica relação de trabalho entre duas ou mais pessoas singularmente consideradas. São as normas sobre as condições de trabalho fixadas através do contrato individual, tácita ou expressamente.

Serão, no entanto, coletivas, quando estabelecidas de um modo geral e abstrato, para a criação de um modelo a ser observado nas relações individuais.

Assim, regulamento coletivo é o conjunto de normas que, em caráter geral, disciplinam a relação de emprego.

Quanto à origem, o regulamento coletivo provém do Estado, dos sindicatos, das empresas, da Organização Internacional do Trabalho e da sociedade em geral.

Quanto à forma, o regulamento coletivo elaborado pelo Estado apresenta-se como lei quando feito pelo Poder Legislativo, ato administrativo, quando determinado pelo Poder 
Executivo, sentença normativa, quando o seu processo de elaboração desenvolve-se perante os órgãos jurisdicionais e tratado quando negociado por dois ou mais Estados. O regulamento coletivo constituído pelos sindicatos têm a forma de convenção coletiva de trabalho. Se, no entanto, é elaborado pela empresa será um regulamento interno de empresa, unilateral ou bilateral, conforme da sua elaboração participem ou não os trabalhadores. Quando é a Organização Internacional do Trabalho que o faz, será, formalmente, uma convenção internacional. Finalmente, se provém da sociedade através de espontânea criação, terá a forma de usos ou costumes.

Quanto ao conteúdo, disciplina as condições de trabalho em geral: salários, férias, indenizações, jornadas de trabalho, adicionais etc.

\section{A Função do Processo Coletivo}

O processo coletivo é um meio de produção de regulamentos coletivos de trabalho pelo Estado, através de um dos seus órgãos, o Poder Judiciário.

Suas origens históricas são encontradas no corporativismo italiano, como parte de um sistema no qual, da valorização dos interesses da produção nacional, resultou uma estrutura político-social dotada de instrumentos considerados necessários para esse fim, em especial a disciplinação do trabalho e do capital em categorias, a institucionalização das corporações e sindicatos e a organização da magistratura do trabalho em condições de declarar, com eficácia geral, normas suficientes para regular a atividade das corporações e dos sindicatos no interesse do Estado e das categorias econômicas e profissionais.

Para a realização dos comandos jurídicos abstratos a Itália reconheceu à magistratura del lavoro a função normativa e confiou ao magistrado um poder por alguns considerado de natureza legislativa. Compreendido como fonte de produção de normas jurídicas, o processo coletivo destinou-se à "formazione del regolamento collettivo giudiziale dei rapporti di lavoro e al controllo ed alla interpretazione astratta di ogni norma collettiva; e la sua disciplina è intensa a far si che il giudice possa provvedere col sussidio di tutti gli elementi oportuni a fargli valutare esattamente gli interessi professionali e nazionali" (NICOLA JAEGER) ${ }^{1}$.

1. Corso di Diritto Processuale del Lavoro, Pádova, Instituto Delle Edizioni Accademiche, 1939. 
Baseando-o em ampla fundamentação doutrinária, FranCESCO CARNELUTTI ${ }^{2}$, combinando convenções coletivas, ordenações corporativas e sentenças normativas, deu-lhes uma estrutura teórica comum e unitária. Definiu as convenções coletivas com a frase que ficou célebre, "un ibrido che ha il corpo del contratto e l'anima della legge". Conceituou as ordenações corporativas como a antítese das convenções coletivas, marcadas pela imp.ositividade e unilateralismo, sem a espontaneidade e a bilateralidade das convenções. As ordenações surgiram como comandos emanados das corporações e as convenções coletivas como ajustes de vontade. As terceiras, as sentenças normativas, foram consideradas formas gerais de criação de normas jurídicas.

CALAMANDREI ${ }^{3}$ observa que os pronunciamentos da magistratura nos processos coletivos "são, em seu conteúdo, a expressão de poderes normativos absolutamente similares àqueles que ordinariamente exercem os órgãos legislativos" Acrescenta que "a magistratura do trabalho formula o direito por classes, de forma geral e abstrata, que é típica dos mandados legislativos. Um elemento jurisdicional existe também aqui: a magistratura do trabalho não pode proceder à formulação de novas normas jurídicas se antes não adquiriu a certeza da existência de uma controvérsia coletiva de modo que também aqui a intervenção do juiz representa o sucedâneo da conclusão do contrato que falta; mas, superada esta fase a magistratura do trabalho, tal como se manifesta não somente nas premissas mas na conclusão da sua decisão, tem neste caso, natureza genuinamente legislativa"

COUTURE " sustenta que a sentença normativa "não só rege as relações já existentes no momento de ser ditada a resolução (conteúdo declarativo), mas, também, atua para 0 futuro (conteúdo constitutivo) como uma verdadeira lei"

Essas são as idéias que estão embasadas no art. 409 do Código de Processo Civil de 1940 da Itália, fiel aos princípios da Carta del Lavoro de 1927, e nos seguintes termos: "Nella formulazione di nuove condizioni di lavoro la magistratura del lavoro giudica secondo equità, contemperando gli interessi dei datori di lavoro con quelli dei lavoratori e tutelando in ogni caso gli interessi superiori della produzione"

2. Lezioni di diritto industriale, teoria del regolamento collettivo dei rapporti di lavoro, Pádova, Cedam, 1936.

3. Instituciones de Derecho Procesal Civil, Buenos Aires, Ejea, 1962, p. 207, trad.

4. Algunas nociones fundamentales del derecho procesal del trabajo, in Tribunales del Trabajo, Santa Fé, 1941, p. 121. 


\section{O Novo Direito Peninsular}

Com o crescimento da teoria da autonomia privada coletiva o direito peninsular sofreu transformações aparentemente substanciais quanto à forma de solução dos conflitos coletivos. Novas normas alteraram a legislação corporativista, dentre as quais o Decreto n. 369, de 24 de novembro de 1944 que revoga todas as disposições legais relativas à constituição, poderes e atividades de sindicatos que remanesciam da estrutura corporativa; o Decreto-lei n. 721, de 9 de agosto de 1943 que suprimiu as corporações, refletindo-se sobre o procedimento jurisdicional; o Código de Processo Civil de 1973 que excluiu o capítulo sobre conflitos coletivos limitando-se a disciplinar o procedimento para solução judicial dos conflitos individuais; e a Constituição italiana de 1947 sepultando o sistema anterior.

Um dos intérpretes do novo pensamento, o jurista GIUGNI, em sua obra Introduzione allo studio del'autonomia colletiva, de 1960, procurando formular uma "dottrina dell'ordinamento intersindacale", ressalta que as relações sindicais devem formar um sistema, uma ordem jurídica não estatal. Essas relações, segundo o mesmo pensador, têm um elemento essencial jurídico que resulta dos conflitos de interesses entre as organizações sindicais, segundo um livre jogo de forças do qual resulta o ordenamento sindical ou intersindical.

Está presente, nessa concepção, a idéia de que a organização sindical italiana contemporânea não abre mão da sua liberdade orgânica. Desse fato, refletem-se efeitos sobre a problemática do processo judicial. A arbitragem facultativa, prevista em convenções coletivas de trabalho aparece como uma forma espontânea e melhor. Formam-se comissões interpretativas que têm a natureza de um colégio de representantes das partes interessadas com poderes para explicitar o sentido das convenções coletivas em torno das quais residirem controvérsias, dotadas, também, de caráter arbitral. Valorizam-se as conciliações sindicais, previstas também nas convenções coletivas, com poderes interpretativos e decisórios ${ }^{5}$.

5. Sobre o novo pensamento dos doutrinadores italianos veja-se GrovanNi TARELLo, Teorie e Ideologie nel diritto sindacale, Milão, Edizioni di Comunità, 1972; MARCEllo DE CRISTOFARo, L'organizzazione spontanea dei lavoratori, Pádova, Cedam, 1972; Pera, Problemi Costituzionali del diritto sindacale italiano, Milão, Feltrinelli, 1960 Gino GIUGNI, Introduzione allo studio della autonomia collettiva, Milão, Giuffrè, 1960. 
Observa, no entanto, CECILIA Assanti ${ }^{6}$ que o princípio da autotutela sindical e a arbitragem não conseguem afastar a ação coletiva perante o Poder Judiciário italiano. Afirma que os conflitos coletivos estão sendo resolvidos na "giurisdizione privata intersindacale e agli organi della giurisdizione ordinaria, potendosi cosi risolvere sia attraverso il sistema di eterotutela tipico della giurisdizione ordinaria"

\section{Origens no Direito Brasileiro}

No Brasil, a sentença normativa, desde 1946 quando a Justiça do Trabalho foi incorporada ao Poder Judiciário e mesmo antes, na sua fase administrativa, é admitida.

Da discussão que se travou em torno dela, dá-nos uma visão ampla a célebre polêmica entre OLIVEIRA ViAnNA e WALDEMAR FERREIRA ${ }^{7}$

Em outubro de 1935 o Ministro do Trabalho submeteu à apreciação do Presidente da República anteprojeto de organização da Justiça do Trabalho encaminhado à Câmara dos Deputados em $1 .^{\circ}$ de dezembro de 1936 e distribuído à Comissão de Constituição e Justiça, sendo relator designado WALDEMAR FERREIRA. No texto era previsto o poder normativo da Justiça do Trabalho contra o qual WALDEMAR FERREIRA se colocou sustentando que a Justiça do Trabalho, no regime constitucional brasileiro (1934), tem a só e única função de dirimir as questões entre empregados e empregadores, regidas pela legislação social. Decide casos concretos. Resolvendo-os, firma os precedentes judiciários, a outros casos aplicáveis, por via de analogia. Por essa forma e nesse sentido, pode criar normas jurídicas, de caso em caso, como a Justiça Ordinária. Fora disso, não. Divergiu do critério do anteprojeto ao propor que nos dissídios coletivos a Justiça do Trabalho teria competência para estabelecer "tabela de salários e normas que regulem as condições de trabalho em determinados ramos de atividade profissional", por entender que tal poder implicaria no reconhecimento de funções legislativa ao órgão judicial. Bateu-se, também, contra a extensão das sentenças normativas a terceiros exercentes de outras atividades, qualidade que, se atribuída à sentença, acabaria desfigurando o seu papel e que é o de meio

6. L'auto tutela sindacale, in SANSEverino \& MAZzonI, Nuovo Trattato di diritto del laboro, Pádova, Cedam, 1971, v. 1, p. 353..

7. Oliverra Vianna, Problemas de Direito Corporativo, RJ., José Olímpio, 1938; Waldemar Ferreira, Prinćpios de Legislą̧ão e Direito Judiciário do Trabalho, SP., 1938. 
de aplicação do direito positivo constituído e não forma de criação de direito geral e abstrato.

Oliveira VianNa, que participou da elaboração do anteprojeto, defendeu-o com invulgar brilho através de uma série de artigos publicados no Jornal do Comércio, em número de 7 (sete), reunidos no seu livro Problemas de Direito Corporativo. A sua divergência com WALDEMAR FERREIRA foi profunda, envolvendo duas concepções jurídicas diferentes. WALDEMAR FERreira defendeu uma teoria clássica, tradicional, exegética e OLIVEIRA VIANNA uma doutrina sociológica, renovadora, dinâmica, inspirada no Realismo Jurídico norte-americano, nos defensores da New Scholl e da Sociological Jurisprudence de Llewellyn, Holes, Brandeis, Stone, Cardozo, aos quais faz referência expressa em suas obras, considerando-os espíritos pragmáticos para os quais o Direito é um instrumento de que devemos nos utilizar para o progresso e a ordem. Com isso, recusa-se a aceitar a rígida separação dos poderes para defender a possibilidade da criação de normas jurídicas pelo Estado e outras fontes; no Estado, pelo Poder Legislativo e outros órgãos, considerando, ainda, válida a delegação de poderes e a descentralização legislativa.

Prevaleceram as idéias de OLIVEIRA Vianna, o poder normativo da Justiça do Trabalho e as normas constitucionais que conferiram aos Tribunais do Trabalho atribuições para decidir os conflitos coletivos de trabalho, tarefa que vem sendo desenvolvida através dos diferentes regimes políticos e econômicos de governo.

\section{Dimensões Atuais}

Discussões hermenêuticas têm surgido porque a Constituição de 1946 dispõe que "a lei especificará os casos em que as decisões, nos dissídios coletivos, poderão estabelecer normas e condições de trabalho", texto que encontra correspondência no art. 134 \& $1 .^{\circ}$ da Constituição de 1967 e na Emenda Constitucional de 1969 da qual resulta a redação do art. 142 $\S 1 .^{\circ}$ da norma constitucional vigente nos mesmos termos.

Duas correntes surgiram. Uma, restritiva do poder normativo, limitando-o aos casos previstos em lei anterior ${ }^{7}$ e outra ampliativa, para a qual a competência da Justiça do

7. ARIon Romita cita parecer de entidade sindical patronal, em seu livro Problemas de Trabalho e Previdência Social, RJ., 1972, p. 93, reunindo juristas que se situam nessa posição, dentre os quais Espínola, Vicente RÁ, Francisco Campos, Pontes de Miranda e outros. 
Trabalho é plena, fundada na própria norma constitucional não limitada por lei ordinária, sendo seus adeptos, dentre outros, BezerRa de Menezes, Joaquim Pimenta, Oliveira Lima, Beresford Martins Moreira, Catharino, Russomano e Cid SITRÂNGULO ${ }^{8}$.

Lei ordinária limitativa do poder normativo dos Tribunais do Trabalho é, unicamente, a lei de política salarial que retira a competência dos Tribunais para fixar livremente as correções salariais coletivas. Para as demais matérias não há limitação nem previsão. Logo, prevalece a genérica autorização constitucional, interpretação, a nosso ver, coincidente com a melhor doutrina.

$\mathrm{Na}$ vida rotineira, os Tribunais vêm elaborando normas gerais, mesmo sem prévia autorização legal, fundando-se no poder constitucional amplo, salvo expressas limitações, com o que se não é maior a sua atividade nos conflitos coletivos salariais, expressiva tem sido nos conflitos coletivos envolvendo outras condições de trabalho.

Seriam hoje sustentáveis os fundamentos que justificaram a sentença normativa?

Coloco-me dentre aqueles que respondem afirmativamente, consideradas as razões que passamos a expor.

Desde logo, afasto qualquer seriedade que se pretenda dar ao argumento de que a sentença normativa deve ser rejeitada porque é instrumento do corporativismo fascista. Aceitá-lo seria o mesmo que afirmar que o filho deve ser repudiado conforme o pai que tem. Assim, o habeas-corpus mereceria repúdio, criação que é do Individualismo quando hoje a idéia é a valorização do social. MoNTAIGNE já dizia que nem sempre é possível julgar as pessoas pelas companhias que têm. Nesse caso, teríamos que condenar os médicos que vivem cercados de doentes. Um fruto bom pode vir de uma árvore má. O que importa é ver se a sentença normativa tem contribuído para a solução dos conflitos coletivos e produzido normas aplicáveis aos contratos individuais e a resposta não pode ser negativa.

Os processos de dissídios coletivos têm contribuído para a criação e o aperfeiçoamento do Direito do Trabalho em nosso

8. Geraldo Bezerra de Menezes, Dissidios Coletivos do Trabaiho e Direito de Greve, RJ:; Borsoi, 1957; JoAquim PImenta, Justiça Normativa para Dissídios Coletivos do Trabalho, prefácio à obra anterior; Oliveira LIMA, Poder Normativo, in Rev. Trabalhista, set./out. 1949, p. 25 a 28; BERESFord Martins MOREIRA, Dissidios Coletivos; Catharino, Poder Normativo da Justiça do Trabalho, in Temas de Direito do Trabalho, 1971; Russomano, Direito Processual do Trabalho, SP., LTR., 1977; Cid Sitrângulo, Conteúdo dos Dissídios Coletivos, SP., LTr. 
País. A estabilidade da gestante, do Direito estrangeiro no Brasil foi instituída mediante sentença normativa e de tal modo que o anteprojeto da CLT, elaborado pela Comissão presidida por SUSSEKIND, acolhe-a como garantia geral. A estabilidade do menor de 10 anos em fase de serviço militar é outra figura que se acrescenta ao nosso Direito pela via jurisdicional. Outros exemplos podem ser indicados como a estabilidade do trabalhador que sofre acidente de trabalho, a obrigatoriedade de fornecimento pelo empregador de envelopes de pagamento discriminando as parcelas pagas ao trabalhador, a distribuição gratuita de uniformes, o salário normativo, o desconto assistencial, a garantia ao substituto do mesmo salário d.o substituído durante a substituição de caráter não eventual, a comunicação escrita dos motivos da dispensa do empregado, a "sobretaxa" de horas extras para a jornada suplementar acima dos permissivos máximos legais, a contagem do tempo de serviço do exercente de mandato sindical afastado do emprego, na sua respectiva antigüidade etc.

Rejeito, também, o argumento inconsistente de que a sentença normativa é figurino ultrapassado porque a Itália a afastou. Não é certo que os conflitos coletivos de trabalho na península, apesar da exclusão formal do novo Código de Processo Civil, do Capítulo sobre conflitos coletivos, possam hoje prescindir do Poder Judiciário quando é sabido que não são raras as situações nas quais os Tribunais italianos vêm sendo chamados a interpretar cláusulas das convenções coletivas de trabalho, conforme dissemos no início.

Não pode ser considerada ultrapassada uma das formas naturais de solução dos conflitos e basta ver a teoria ensinada com muita clareza por AlCALÁ-ZAMORA Y CASTILLO em sua obra Proceso, auto composición y autodefensa, para que nenhuma dúvida possa ficar quanto aos "modos de desembocadura dos litígios", individuais ou sociais.

Os conflitos precisam ser resolvidos. Os modos de solução classificam-se em três: a autodefesa, a autocomposição e a heterocomposição. $\mathrm{O}$ primeiro consiste na solução direta pelos próprios litigantes e pela imposição de um sobre outro. 0 segundo, na solução que também é direta, mas não pela imposição e sim pelo acordo. O terceiro na solução por uma fonte suprapartes. Há um iter a ser percorrido no procedimento de solução dos conflitos coletivos trabalhistas, abrangendo em suas fases as três formas e não prescindindo da última, a heterocomposição. Esta será indispensável sempre 
que as partes não encontrem diretamente o caminho para a composição.

A jurisdição trabalhista é um poder social de decidir com força jurídica as lides de natureza trabalhista. Esse poder atende à finalidade de vida social segundo o bem comum. Surgiu da necessidade de dotar a sociedade de um sistema de solução de questões trabalhistas. Da gradativa transposição da autodefesa, ainda indispensável, para a solução organizada e emanada não dos interesses isolados dos participantes do conflito, mas de um terceiro imparcial, desinteressado, resultou a institucionalização da idéia de jurisdição trabalhista, hoje irreversível. A jurisdição pode, como poder institucionalizado, quebrar resistências, nem sempre entre nós ainda hoje quebradas e que só o serão de modo pleno e satisfatório na medida da conscientização do seu significado. $O$ processo de evolução cultural de um povo conduz, necessariamente, à aceitação do poder jurisdicional, a não ser que prevaleça o entendimento de que a violência é forma prioritária na composição dos conflitos, como se fosse possível tal concepção. A intervenção harmonizadora da jurisdição pode reduzir a intensidade dos conflitos numa dada ordem social por mais defeituosa que seja a formulação que dê aos problemas econômico e de distribuição de riquezas A jurisdição trabalhista é um instrumento que, embora relacionado com a problemática econômica, não deve ser vista como meio para pôr fim à questão social, mas sim como canal indispensável de atendimento às reivindicações trabalhistas que são justas e oportunas em um litígio coletivo.

Pelos mesmos motivos que me levam a entender que há um iter a ser percorrido na solução dos conflitos trabalhistas, a sentença normativa não pode ser vista como substituta das negociações coletivas, e sim como parte de um procedimento mais amplo que não prescinde das negociações diretas autocomposição —, só se justificando à falta do acordo, caso em que é necessária a interferência heterônoma-heterocomposição. Não é por outra razão que a teoria alemã considera o dissídio coletivo como sucedâneo da convenção coletiva frustrada.

De outro lado, é, também, forçada a afirmação de que ao proferir a sentença normativa o Tribunal deixa de cumprir a sua função que é restrita à aplicação do direito positivo pré-constituído. Em outras palavras, a sentença normativa representaria injustificável invasão das funções pertinentes ao Poder Legislativo pelo Poder Judiciário. Também aqui penso 
que tal entendimento não pode ser acompanhado a menos que desavisadamente.

Não é mais possível recusar a função criativa da atividade judicial. A teoria contemporânea defende a maior flexibilidade de atuação do magistrado diante dos problemas que tem que resolver. A teoria clássica do juiz escravo da lei justificava-se à luz do Código de Napoleão mas não tem base na doutrina moderna, como mostra com toda a clareza a obra de BELAID, Essai sur le pouvoir createur et normatif du juge (Paris, LGDJ, 1974). Para o autor, a jurisdição é valorizada como fonte de Direito. 0 juiz tem poder criativo, para alguns fundado na delegação do próprio legislador, age com e por eqüidade, na qual encontra, sem nenhuma dúvida, uma transferência do poder de legislar para o caso concreto.

Quando OLIVEIRA VIANNA invocava a Escola Sociológica fazia um trabalho pioneiro que ainda hoje não pode ser desvalorizado. Ao contrário, tem toda a atualidade. Daí porque na área trabalhista com maior razão, não é possível desconhecer os seus estudos como também são expressivas as novas formulações que embora não destinadas diretamente ao nosso campo, tem nele um natural escoadouro. Dentre estas, a Nueva Filosofia de la Interpretación del Derecho e a lógica razoável, de RECASÉns SICHES, indicativa da mesma postura criativa do juiz moderno.

Incluo, dentre as contribuições contemporâneas e que dão ampla fundamentação às idéias que justificam a sentença normativa, a teoria da sentença como norma, com ampla aceitação de juristas como KELSEN ${ }^{9}$, GARCiA MAYNES ${ }^{10}$ GOLDSCH MIDT ${ }^{11}$, ABELARDO TORRE ${ }^{12}$, RODRIGUES ARIAS ${ }^{13}$, Martin Oviedo ${ }^{14}$, Miguel Reale ${ }^{15}$ e o próprio Siches ${ }^{16}$.

Finalizando, penso que o Direito não é obra exclusiva do Legislador e a lei não resume todo o fenômeno normativo.

9. Teoria Pura do Direito, trad., 2. ${ }^{\mathrm{a}}$ ed. Coimbra, Armênio Amadi Editor, 1962, Col. Studium.

10. Introducción al estudio del derecho, 19. ${ }^{\mathrm{a}}$ ed., México, Porrua, 1972, p. 92 .

11. Introducción al derecho, trad., $3 .^{\mathrm{a}}$ ed., Buenos Aires, Depalma, 1967, p. 190.

12. Introducción al derecho, 6. ${ }^{a}$ ed., Buenos Aires, Abeledo-Perrot, 1972, p. 147.

13. Ciencia y Filosofia del Derecho, Buenos Aires, EJEA, 1961, p. 530.

14. Formación y Aplicación del Derecho, Madri, IEP, 1972, p. 94.

15. Liçōes Preliminares de Direito, SP., Bushatsky, 1973, p. 161.

16. Op. cit. 
Deve ser pluralista a organização da ordem jurídica, descentralizando-se em uma multiplicidade de formas e de fontes que se combinam com a supremacia das normas do Estado e do Poder Legislativo. A lei nunca foi a única fonte, nem historicamente a primeira, porque os primeiros conflitos foram solucionados segundo os costumes.

Dessas observações não se pode fugir ao repensar sobre a sentença normativa, muito menos ignorar as transformações operadas no Direito Processual Civil com a teoria da tutela jurisdicional dos grupos sociais ou a teoria da proteção dos direitos difusos que certamente acarretará uma revolução nos conceitos tradicionais de ação, representação processual, coisa julgada e jurisdição, tendendo para novas concepções, coincidentemente as mesmas que justificam a sentença normativa.

\section{Bibliografia.}

Aranguren, Aldo. Controversie individuali e controversie colletive di lavoro, in Sanseverino e Mazzoni, Nuovo trattado di diritto del lavoro, Padova, Cedam, 1975.

ARIAS, Rodrigues, Ciência y filosofia del derecho, BA., Ejea, 1961.

Aroca, Juan Montero, Introducción al derecho procesal, Madri, Tecnos, 1976.

Belaid, S., Essai sur le pouvoir créateur et normatif du juge, Paris, LGDJ., 1974.

Brimo, Albert, Les grandes courants de la philosophie du droit et de l'Etat, Paris, Pedone, 1968.

Cabanellas, Derecho normativo laboral, Ba., Bibliográfica Argentina, 1966.

Cabanellas e Russomano, Solución de los conflictos colectivos, tese, 1977.

CALAMANDreI, La natura giuridica delle decisioni della magistratura del lavoro in Italia, in Studi sul processo civile, Padova, 1934.

CAPPelletti, Mauro, Formações sociais e interesses dos grupos ante a justiça civil, Rivista di diritto processuale a. Xxx, II série n. 3 . fls. 361 e 402 , jul/set. 1975.

Carnelutti, Francesco, Sistema del diritto processuale civile, Padova, Cedam,

1929; Lezioni di diritto imdustriale, teoria del regolamento collettivo dei rapporti di lavoro, Padova, Cedam, 1936.

CAStullo, Niceto Alcalá-Zamora y, Proceso, auto-composición y autodefensa, México, Unam, 1970.

Catharino, José Martins, Poder normativo da Justiga do Trabalho, in Temas de Direito do Trabalho, RJ., Ed. Trabalhistas, 1971.

Cesarino Júnior, Direito Processual do Trabalko, RJ. e SP., Freitas Bastos, 1942.

Costa, Orlando Teixeira, Sistemas de Soluçāo dos Conflitos Coletivos, sP., LTr..

Gaudemet, Jean, Institutions de l'antiquité, Paris, Sirey, 1967. 
JAEGer, Nicola, Corso di diritto processuale del lavoro, Padova, Instituti delle Ediziono Accademiche, 1933.

Lara, Cipriano Gomes, Teoria General del Proeesso, México, Unam, 1974.

Maynes, Garcia, Introducción al Estudio del Derecho, México, Porrua, 1971.

Menezes, Geraldo Bezerra, Dissidios Coletivos do Trabalho e Direito de Greve, RJ., Borsoi, 1957.

Nascimento, Amauri Mascaro, Teoria da Norma Juridica Trabalhista, SP., LTr., 1977; Conflitos Coletivos de Trabalho, SP., Saraiva, 1978.

Ossorio Y FloRIT, Consideraciones a la solución judicial de los conflictos colectivos del trabajo, III Congresso Nacional de Derecho del Trabajo y de la Seguridad Social, 1965.

Puech, Luiz Roberto de Rezende, Da Sentenca Normativa na Justiça do Trabalho, LTr., SP., n. 33/371.

RASelli, Alessandro, La magistratura del lavoro, giurisdizione ed azione, Padova, Cedam, 134.

Reale, Miguel, o direito como experiência, SP., Saraiva, 1968.

RIPERT, Georges, Les forces créatrices du droit, Paris, LGDJ., 1955.

Rodriguez, Americo Pla, Los conflictos del trabajo, Montevideo, 1947.

Romita, Arion Sayon, Problemas de Trabalho e Previdência Social. RJ., Ed. Rio, 1972.

Ruprecht, Conflictos colectivos del trabajo, BA., Abeledo-Perrot, 1967.

Russomano, Mozart Victor, Direito Processual do Trabalho, SP., LTr., 1977.

Srches, Luis Recaséns, Nueva filosofia de la interpretación del derecho, México, Porrua, 1973.

Silva Teles, Goffredo, Filosofia do Direito, São Paulo, Max Limonad, s/d.

Sitrângulo, Cid José, Conteúdo dos Dissidios Coletivos, sP., LTr., 1978.

Vianna, Oliveira, Problemas de Direito Corporativo, RJ., José Olímpio, 1938.

Vilhenà, Paulo Emílio Ribeiro, Contrato de Trabalho com o Estado, tese, 1965. 